\title{
The Impact of Job Burnout on the Performance of Staff Member at King Abdul-Aziz University
}

\author{
Wafaa Mohammed Ahmed Bin Zaid \\ King Abdul-Aziz University \\ P.O. Box 21484 \\ Jeddah 17476 \\ Saudi Arabia
}

\begin{abstract}
Job burnouts have been associated with reduced employee satisfaction and performance. Establishing the causes of job burnout and its effect on staff members of the King Abdul-Aziz University, Jeddah, Saudi Arabia, was the intention of the present investigation. Three dimensions of burnout were assessed: exhaustion, depersonalization, and personal accomplishment. It was hypothesized that each of the three had direct impacts on workplace satisfaction and performance. The research assumed a quantitative approach using a descriptive design. Data from 500 individuals who work at the institution were randomly sampled and analyzed; and information obtained through questionnaires. The mean exhaustion level of the sample was $2.95(\mathrm{std}$, dev. $=0.77)$ while that for depersonalization and personal accomplishment were $2.09(\mathrm{std}$, dev. $=0.77)$ and $3.83(\mathrm{std}$, dev. $=0.53)$ respectively. The average staff performance was 3.36 (std, dev. =0.60). Significant associations were established between performance and each of the dimensions.
\end{abstract}

Keywords: burnout, emotional exhaustion, depersonalization, performance, personal accomplishment.

\section{Introduction}

Job burnout is a situation that results from repeated exposure to instances of work-related stress characterized by known physical, emotive and mental exhaustion. Job burnouts continue to affect many workers in several organizations. This situation influences the performance of institutions in addition to causing undesirable impacts on individual staff members. Risk factors that have been linked to the condition include inadequate motivation absence of organizational support, incompetence and lack of clarifications, unrealistic expectations, and increased responsibilities. Its manifestations include withdrawal symptoms, interpersonal controversy, low performance, family problems, and health issues. Therefore, all managers need to implement suitable strategic plans that will assist them with providing conducive workstation environment to protect employees from experiencing problems associated with burnouts(Khdour et al., 2015).

Job burnout is investigated by experts throughout the past years. This issue can be found in the social community and workstations. In fact, job burnout is established on continued stresses; and it might make the workers feel shortage of power. Job burnout is frequently found in the profession in which workers spend much time and have frequent direct contacts with clients. For instance, professionals in the education sector have high chances of developing the condition. We can classify king Abdul-Aziz University Staff members among those who are in a direct contact with customers since they spend much more time with their students and their directors. Also, they face stress and a huge amount of psychological pressure. These issues could be signs of a patient who suffers from Job burnout strains which result in reducing of functioning excellence and giving services. Consequently, the present study is trying to examine this issue: the impact of job burnouts on the performance of employees at the King Abdul-Aziz University. It also tries to find out if there is a relationship between Job burnout dimensions and the performance of KAU Staff Member.Three dimensions of job burnouts have been identified in the literature: emotional exhaustion, depersonalization, and the absence of personal accomplishment. The first one appears to be the dominant aspect of occupational burnout (Gorji, 2011).

\subsection{Problem Statement}

Previous studies showed that burnout resulted in negative significant impact on the organization's productivity. Burnout starts in weak cooperation, unsuitable work environment and lesser self-respect which results in psychological illnesses "anxiety disorder and pressure" as well as physical diseases "heart sicknesses". The consequences of burnout for an organization contain lack of job performance, loss of job satisfaction, and low organizational achievement and increased absence and high turnover of employees. 
Moreover, pressure, stress and emotional difficulties associated to jobs can cause more physical and mental consequences on employees. Although burnout has been a remarkable and focal point for many researches, there is still lack of studies in Saudi Arabia handle this phenomenon.

Therefore, the present study is trying to carefully study this phenomenon: The influence of Job burnout on the performance of King Abdul-Aziz University Staff Members; and to investigate the relationship between Job burnout dimensions: exhaustion, depersonalization, personal accomplishment and the Staff Member' Performance at KAU.

\subsection{Objectives of the study}

1. To point out the level of Job Burnout among (KAU) Staff Members.

2. To identify the extent of job burnout affecting the performance of (KAU) staff members.

3.To analyze the impact of each of the job burnout factors: exhaustion, depersonalization, and personal accomplishment on performance of (KAU) Staff Members.

\subsection{Significance of the study}

The importance of this study stems from the scarcity of previous studies to the researcher's knowledge, in the Kingdom of Saudi Arabia, despite the many studies conducted in different parts of the world onjob burnout. In addition, the present research is anticipated to be useful for managers and administrators who can comprehend the existence of the of job burnout phenomenon among workers and allocate appropriate work to their employees. Moreover, it is anticipated to be useful for human resources who play significant role in the accomplishment of their responsibilities effectively in their universities in a way that develops quality of the service provided. Likewise, findings of this study will help human resource managers to implement appropriate and suitable work to employees; and help employees to deal with stress-related problems at work. In addition, this study is anticipated to enhance knowledge and experience for the psychologist. Finally, it might fill the gaps in the field; and offer a guideline to researchers to comprehend the importance of job burnout phenomenon and its effect on the Staff member.

\subsection{Hypothesis of the study}

1. Hypothesisone: There is significant and negative impact of emotional exhaustion dimension of job burnout on (KAU) Staff Members' performance.

2. Hypothesis two: There is significant and negative impact of depersonalization dimension of job burn out on (KAU) Staff Members' Performance.

3. Hypothesis three: There is significant and positive impact of personal accomplishment dimension of job burnout on (KAU) Staff Members' performance.

\subsection{Research Model}

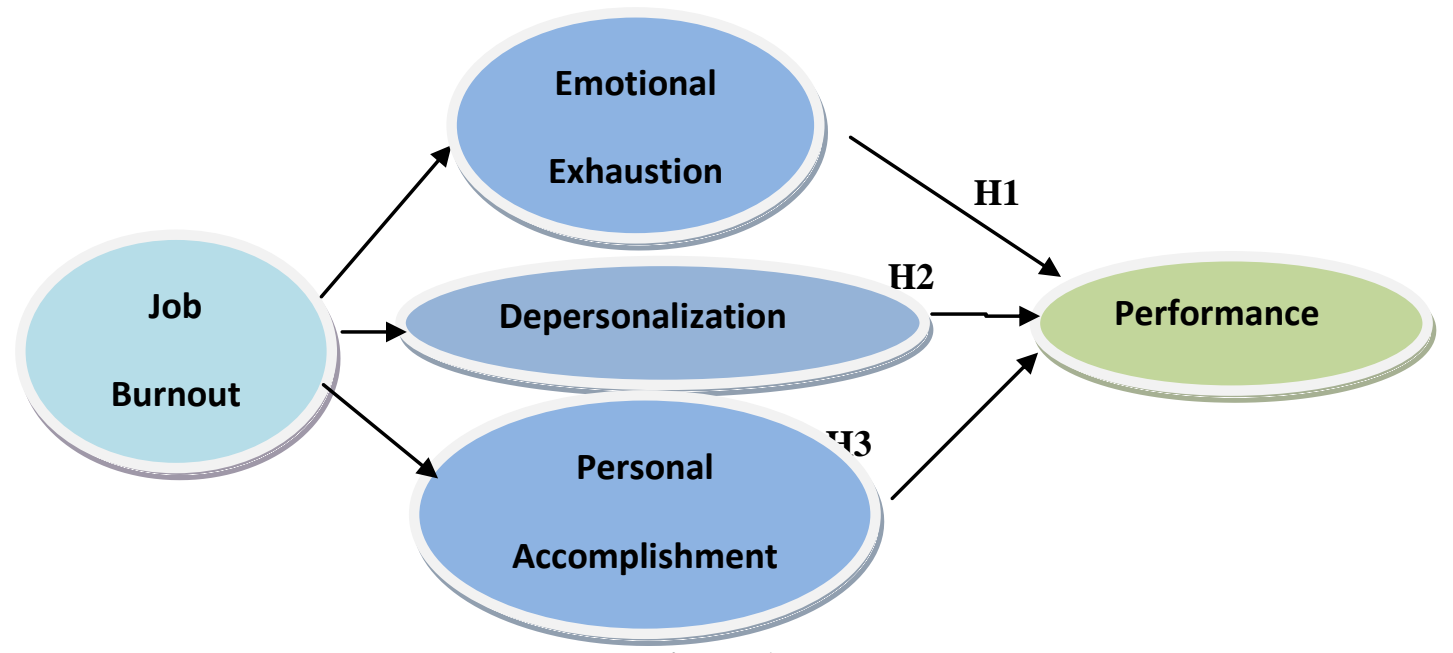

\section{Literature review}

Figure 1: Research Model

\subsection{Introduction of burnout}

There was no clear-cut definition of the burnout concept, though there were an extensive variety of ideas and thoughts concerning what it was. Nevertheless, there was an essential agreement regarding three main dimensions of the burnout experience, and consequent research on this matter led to the expansion of a multidimensional theory of burnout (Maslach, 1982). Work-related burnout from indefinable, long-lasting job stress was first defined in (1974) by Freudenbergon staff burnout from volunteers in an unrestricted medical clinic. Freudenberg (1974) is recognized with 
discovering the term burnout and nominated the features of proficient burnout in the setting of physical and behavioral signs as follows: growing anger, frustration, doubt and fascination regarding partners' impacts on one's own personal career hopes and desires, extreme inflexibility and rigidity in application, and the presence of physical appearance of one who suffers from hopelessness and depression.

Burn out is a reaction to chronic, job-related stress known by physical, emotive and mental exhaustion, which results from circumstances of work, job strain and/or self-justifying coping (Schaufeli \& Enzmann, 1998). In a brief point, burnout can be well-defined as feelings of tiredness, a suspicious attitude concerning people involved in the work and through a concentrated personal accomplishment or work efficiency (Lee \&Ashforth, 1993).Burnout has been acknowledged theoretically and conceptually as a multidimensional disease of emotional exhaustion, depersonalization (cynicism) and reduced personal achievement also called lack of personal effectiveness (Schaufeli \& Enzmann, 1998).

Zang and Feng (2011) stated that the plans for stopping job burnout are linked to the individuals or to the organization. Individual plans which prevent job burnout have usually programs for growing job proficiency, different relaxation exercises, identifying the goal and time management, productive rational and unawareness of passive thinking, employing humor, having a variety of activities at work, having and maintaining support networks, familiarizing to upsetting events, and self-monitoring one's stress (Demir et al., 2003; Espeland, 2006; Maslach et al., 2001).

In organization level, this plan usually emphases on methods like reconstructing job duties, goals of examining jobs, declining job demands and attendance in judgment making; using exact methods of selecting and engaging human capitals; possessing appropriate training courses(Wendy, 2009). Those persons who link in anticipation programs regularly faced few quantities of pressure in association with others.

\subsection{Dimensions of burnout}

\subsubsection{Emotional Exhaustion}

Emotional exhaustion has been recognized as the leading feature of burnout (Maslach et al., 2001). It signifies to the over-extension and reducing of resources connecting to feelings. This phase has signed such, fear, nervousness, and annoyance, and touchiness, lack of vitality, sense of weakness, and exhaustion. Emotional exhaustion is the first phase of burnout and has been well-known as the feeling of being passionately over-extended and tired by one's work (Maslach et al., 1996). Overall signs of emotional exhaustion are a headache, tiredness, and feeling of powerlessness.

\subsubsection{Depersonalization}

It's related to negative responses of the individuals toward different working conditions which cause creation of negative view, the feeling of being unacceptable and in the end creation of a gap between the individuals and their jobs(Maslach et al, 1996).It is an effort to put space between oneself and capability receivers by actively disregarding the potentials that mark them sole and charming people. Their needs are further controllable when they are wellthought-out measured objects of one's work. Outside of the human services, people use cognitive separation by developing an unimportance or pessimistic attitude when they are fatigued and disheartened. Isolation is such a direct interaction to exhaustion that a strong relationship from exhaustion to "cynicism": depersonalization"; which is showed reliably in burnout study, across an extensive range of institutional and professional situations (Lee \&Ashforth, 1993).

\subsubsection{Decrease of personal accomplishment}

Lack of personal aptitude or lack of personal achievement is the last stage of burnout where the employees have entirely burnt out and require a clinical care with sense of failure. The employee destructively assesses their capability and attainments in the workplace (Maslach et al, 1996). This stage comprises two aspects, job capability and, the achievement in one's work. The worker assesses his achievements in the specialized life detrimentally. An individual feels unhappy and dissatisfied with her/his work. Inefficacy last in despair, low self-confidence, and incapability to deal with work stresses. The employee feels hopeless which results in low self-respect and little capability and low efficiency (Maslach et al., 2001).

\subsection{Measurement of Burnout}

According to Maslach et al., (1996) the famous burnout assessing tool is the Maslach Burnout Inventory MBI questionnaire. In fact, the MBI includes the three above stated measurements of burnout: personal achievement, emotional tiredness, and depersonalization. As stated by Halbesleben (2003), the MBI was planned to deal with burnout in social services area. Nevertheless, it has been modified to handlea broader range of jobs. The MBI consists of twenty-two items. The MBI-GS, however, has modified some items with a more general phrasing, and handle a separate attitude towards the job somewhat than towards the persons. An extensive variety of professions has been interrogated, experiential and surveyed before building this multidimensional burnout assessment device. 
The MBI-GS multidimensional approach implies that it may be more effective to consider how to reduce the likelihood of emotional exhaustion, or to prevent the tendency to depersonalize, or to enhance one's sense of accomplishment, rather than to use a more general stress reduction approach (Maslach \& Schaufeli,1993).

\subsection{Previous Studies}

Gorji(2011) investigated the relationship between the impact of job burnout dimension on employees' performanceof 250 bank workersin Golestan region in Iran. The findings have shown that in addition to the high amount of job burnout through personnel's, other characteristics like passionate tiredness and depersonalization has a certain reverse effect on the performance of an individual. This means that the conduct of the personnel's decrease according to increasing emotional exhaustion, depersonalization and vice versa. Also, it became obvious that the deficiency of the Individual success isn't associated with the individual's achievement.

In Poland, Kugiejko (2015) investigated the lack of managerial support which relates to the group of variables describing characteristics of 141 teachers' burnout at Polish schools using mix method approach. Special emphasis was given to the age and inclination to exhaustion at work, lack of inspiration and feeling of obstruction. The study presented that in most cases instructors within the range of the research confirmed not to feel burnout. However, fairly less than a half of them declared to working under daily stress and in fact experiencing the process of the job burnout without even understanding it.

Moreover, Naser et al.,(2015) studied the Effect of Job Burnout on Employees' Satisfaction in Jordanian Universities; using a descriptive analytical method through a comparative study between Governmental Universities and private ones, the questionnaire was distributed to a sample of (200) administrators of the organizational staff. The study has presented that the level of job burnout experienced by the administrative staff in the university sector was more than average; showed that low personal performance dimension has placed the first as the most persistent job burnout dimension followed by physical and emotional overtiredness; lastly, negative attitude towards relationships. It found that the level of job burnout in public universities was higher.

In addition, Afzalur Rahim (2016) investigated the relationships of effective conflict management strategy and less active conflict management strategy. Data consisted of 869 academics of MBA undergraduate students who had jobs. Findings displayed that a combination of relevant conflict-handling styles by attendant can guide to a useful conclusion, such as decreased job burnout. It is also predicted that the use of effective conflict management strategy by staffs might lead to more advantageous consequences for the institution.

Moreover, Bakker and Oerlemans (2016) concentrated on the relationship between discrepancies concerning selfrepresentation, the burnout syndrome, and job contentment, among Italian correctional officers. Link Burnout Questionnaire (LBQ) was used for data collection. Finding showed that burnout level was high and decreased job satisfaction. Finally, burnout facilitated the relationship between self-representation inconsistencies and job contentment. Higher discrepancies decreased satisfaction with one job by multiplying burnout levels.

The current study smears the association between Job Burnout and KAU staff member performance. The difference between the current study and the preceding studies is the sample size and the scope of the research. All the previous studies were accompanied by small sample size while this study will be directed in large sample size. Nevertheless; this study is similar to the earlier studies in following the quantitative approach method.

\section{Research methodology}

\subsection{Introduction}

The study sought to investigate the impact of job burnout dimensions (emotional exhaustion, depersonalization, personal accomplishment) on the performance of (KAU) staff members; and to measure the level of job burnout and the level of performance. The resources of the primary data were collected using survey questionnaire method which was designed based on (Maslach 1982, 1998) theory and distributed to the staff members of (KAU) in Jeddah, KSA. Descriptive Statistical Techniques and inferential statistics method that included regression analysis were used to test the research hypotheses.

\subsection{Research instrument}

The questionnaire contains three main sections. The first section consisted of three demographic variables (gender, age, and experience).The second section included (21) items that measure the state of burnout for the sample of the study of (KAU) staff members (independent variable) through three sub-dimensions: emotional exhaustion: (9 items); depersonalization: (5 items); and decrease of personal accomplishment: (7 items). 
The third section included (18) items that measure the performance of the sample of the study (dependent variable) under the effect of burnout. Respondents were asked to read each item and select one of the choices as follows: - Score 5: For the (Strongly agree); - Score 4: For the (Slightly agree); - Score 3: For the (Neither agree or disagree); - Score 2: For the (Slightly disagree); - Score 1: For the (Strongly disagree).

\subsection{Population and Sample}

The research population includes all of the Staff Members in King Abdul-Aziz University, in Jeddah. A simple random sample technique was acquired using the electronic web of the university; and around (500) valid responses were received.

The characteristics of the sample of the study are presented as shown in tables (1,2 and 3) below:

Table (1) Participants distribution according to Gender

\begin{tabular}{|c|c|c|}
\hline Gender & Frequency & Percentages\% \\
\hline Male & 196 & 36.2 \\
\hline Female & 304 & 60.8 \\
\hline Total & 500 & $100.0 \%$ \\
\hline
\end{tabular}

Table (1) shows that majority of participants are female $(60.8 \%)$.

Table (1) Participants distribution by Age

\begin{tabular}{||c|c|c|}
\hline Age classes & Frequency & Percentages\% \\
\hline Less than 30 years & 76 & 15.2 \\
\hline 30- to less than 45 & 313 & 62.6 \\
\hline 45- to less than 60 & 97 & 19.4 \\
\hline 60 and more & 14 & 2.8 \\
\hline Total & 500 & $100.0 \%$ \\
\hline
\end{tabular}

Table (2) displayed the staff members distribution by age, and it was observed that, the staff members in age class (30to less than 45$)$ comprised the majority with $(62.6 \%)$.

Table(2) Participants distribution by experience

\begin{tabular}{||c|c|c|}
\hline \multicolumn{1}{|c|}{ experiences } & Frequency & Percentages\% \\
\hline 1-to 5 years & 128 & 25.6 \\
\hline 6-to 10 years & 171 & 34.2 \\
\hline More than 10 years & 201 & 40.2 \\
\hline Total & 500 & $100.0 \%$ \\
\hline
\end{tabular}

Table (3) showed that majority of participants have experience of more than 10 years $40.2 \%$ ).

\subsection{The survey scale reliability}

As shown in Table (4), the total Cronbach's alpha for the study fields was (0.75) which was highly sufficient to guarantee that the survey scale has a very high reliability.

Table (4): Cronbach's Alpha for the Study Dimensions

\begin{tabular}{|l|l|l|}
\hline Dimensions & No of items & Cronbach's Alpha coefficient \\
\hline Dimension one: burnout & 21 & 0.721 \\
\hline Subscale1: emotional exhaustion & 9 & 0.853 \\
\hline Subscale2: depersonalization & 5 & 0.792 \\
\hline Subscale3: Personal accomplishment & 7 & 0.717 \\
\hline Dimension two: Performance & 18 & 0.872 \\
\hline Overall reliability & 39 & 0.750 \\
\hline
\end{tabular}

\section{Analysis of the Results}

\subsection{Section one: descriptive statistics}

The main objective behind conducting the descriptive statistics is to assess the rate of burnout among (KAU) staff members; and its impact on their job performance by analyzing the three dimensions: (emotional exhaustion, 
depersonalization, personal accomplishment). To conduct data analysis, the means, and standard deviations are used. The results of this analysis are presented as in the following tables:

Table (5) Participants responses with regard to emotional exhaustions

\begin{tabular}{|c|l|c|c|c|}
\hline $\begin{array}{l}\text { Item } \\
\text { No. }\end{array}$ & Emotional exhaustion & Means & $\begin{array}{l}\text { Standard } \\
\text { deviation }\end{array}$ & Ranking \\
\hline 1 & I feel emotionally drained from my work. & 3.30 & 1.15 & 3 \\
\hline 2 & I feel that my work has exhausted emotionally. & 3.69 & 1.10 & 2 \\
\hline 3 & I feel used up at the end of the work day. & 3.20 & 1.21 & 4 \\
\hline 4 & $\begin{array}{l}\text { I feel fatigued when I get up in the morning and } \\
\text { have to face another day in the morning }\end{array}$ & 2.69 & 1.14 & 5 \\
\hline 5 & $\begin{array}{l}\text { Working with people all day is really a strain for } \\
\text { me. }\end{array}$ & 2.40 & 1.14 & 8 \\
\hline 6 & I feel burned out from my work. & 2.69 & 1.25 & 6 \\
\hline 7 & I feel frustrated by my job. & 3.94 & 1.00 & 1 \\
\hline 8 & I feel I'm working too hard on my job. & 2.61 & 1.18 & 7 \\
\hline 9 & I feel like I'm at the end of my rope. & 2.00 & 1.03 & 9 \\
\hline & Overall mean & 2.95 & 0.77 & \\
\hline
\end{tabular}

Table (5) showed that the overall mean value of the impact of emotional exhaustion on KAU staff members' performance is equal to (2.95) with (St. Dev. 0.77); which indicated that they are moderately impacted by emotional exhaustion. In addition, majority of staff members confirmed that they feel frustrated by their job. On the other hand, they did not agree that working with people all day is really a strain for them, or they feel like they at the end of their rope.

Table (6) Participants responses with regard to depersonalization

\begin{tabular}{|c|l|c|c|c|}
\hline $\begin{array}{l}\text { Item } \\
\text { No. }\end{array}$ & Depersonalization & Means & $\begin{array}{l}\text { Standard } \\
\text { deviation }\end{array}$ & Ranking \\
\hline 10 & $\begin{array}{l}\text { I feel I treat some recipients as if they were } \\
\text { impersonal objects. }\end{array}$ & 2.02 & 1.04 & 3 \\
\hline 11 & $\begin{array}{l}\text { I've become more callous towards people since I } \\
\text { took this job. }\end{array}$ & 1.95 & 0.99 & 4 \\
\hline 12 & I worry that this job is hardening me emotionally. & 2.18 & 1.14 & 2 \\
\hline 13 & I don't really care what happens to some students. & 1.84 & 0.92 & 5 \\
\hline 14 & $\begin{array}{l}\text { I feel recipients blame me for some of their } \\
\text { problems. }\end{array}$ & 2.48 & 1.13 & 1 \\
\hline & Overall mean & 2.09 & 0.77 & \\
\hline
\end{tabular}

Table (6) showed that the overall mean value of the impact of depersonalization on KAU staff members' performance is equal to (2.09) with (St. dv: 0.77), which indicated that they did not agree that depersonalization has any impact on their performance, which means that the majority of them feel normal, while doing their jobs in the university.

Table(7) Participants responses with regard to personal accomplishment

\begin{tabular}{|c|l|c|c|c||}
\hline $\begin{array}{l}\text { Item } \\
\text { No. }\end{array}$ & Personal accomplishment & Means & $\begin{array}{l}\text { Standard } \\
\text { deviation }\end{array}$ & Ranking \\
\hline 15 & $\begin{array}{l}\text { I can easily understand how my recipients feel about } \\
\text { things. }\end{array}$ & 3.42 & 0.95 & 7 \\
\hline 16 & I deal very effectively with the problems of my recipients. & 4.20 & 0.75 & 1 \\
\hline 17 & $\begin{array}{l}\text { I feel I'm positively influencing other people's lives } \\
\text { through my work. }\end{array}$ & 3.67 & 0.95 & 6 \\
\hline 18 & I can easily create a relaxed atmosphere with my students. & 3.77 & 0.93 & 5 \\
\hline 19 & I feel exhilarated after working closely with my students. & 3.82 & 0.86 & 3 \\
\hline 20 & I have accomplished many worthwhile things in this job. & 3.79 & 0.85 & 4 \\
\hline 21 & "In my work, I deal with emotional problems very calm. & 4.16 & 0.79 & 2 \\
\hline & Overall mean & 3.83 & 0.53 & \\
\hline
\end{tabular}

Table (7) showed that the overall mean value of the impact of personal accomplishment on KAU staff members' performance is equal to (3.83) with (St. dv: 0.53), which indicated that their personal accomplish is positive during performing their job in the university and not in decrease. 
Table (8) The staff members views with regard to their performance

\begin{tabular}{|c|c|c|c|c|}
\hline $\begin{array}{l}\text { Item } \\
\text { No. }\end{array}$ & Staff Members' Performance & Means & $\begin{array}{l}\text { Standard } \\
\text { deviation }\end{array}$ & Ranking \\
\hline 1 & $\begin{array}{l}\text { I have desire and willingness to process over thy } \\
\text { assignment's tasks. }\end{array}$ & 3.79 & 1.13 & 4 \\
\hline 2 & Potential skills matching my professional rank. & 4.04 & 0.94 & 2 \\
\hline 3 & $\begin{array}{l}\text { I am capable to deal with advanced technology and } \\
\text { communication systems. }\end{array}$ & 4.50 & 0.62 & 1 \\
\hline 4 & $\begin{array}{l}\text { Management provides excellent touch for developing } \\
\text { ideal relationship between students and teaching staff. }\end{array}$ & 3.35 & 1.20 & 7 \\
\hline 5 & $\begin{array}{l}\text { Responsibilities of each member in organization chart } \\
\text { known and identified distinctly. }\end{array}$ & 2.92 & 1.22 & 16 \\
\hline 6 & $\begin{array}{l}\text { The policy of teaching committee obliges and sustain in } \\
\text { clarifying assignment duties. }\end{array}$ & 2.99 & 1.18 & 13 \\
\hline 7 & $\begin{array}{l}\text { Management design periodical training course in } \\
\text { recognition to classify posts standardization. }\end{array}$ & 2.99 & 1.13 & 14 \\
\hline 8 & $\begin{array}{l}\text { I am well aware of the tasks required in detail, committed } \\
\text { and adherence to accordingly. }\end{array}$ & 3.56 & 1.10 & 5 \\
\hline 9 & $\begin{array}{l}\text { There are competition conflicts in the field of the work } \\
\text { between colleagues against some responsibilities. }\end{array}$ & 3.33 & 1.08 & 8 \\
\hline 10 & $\begin{array}{l}\text { I am capable to find alternative solutions to resolve } \\
\text { business difficulties. }\end{array}$ & 3.89 & 0.78 & 3 \\
\hline 11 & $\begin{array}{l}\text { The management desk sustains conception ideas raised by } \\
\text { teaching staff with regard to enhancement performance } \\
\text { quality. }\end{array}$ & 3.18 & 1.09 & 11 \\
\hline 12 & $\begin{array}{l}\text { I care management risk while doing tasks though in } \\
\text { different and innovatively modes guaranteed successful. }\end{array}$ & 3.55 & 0.99 & 6 \\
\hline 13 & $\begin{array}{l}\text { Teaching staff those provide new opinions consider useful } \\
\text { for the work within frame department have been } \\
\text { rewarded. }\end{array}$ & 2.70 & 1.12 & 18 \\
\hline 14 & $\begin{array}{l}\text { I know my duties, responsibilities and required tasks in } \\
\text { accordance to work's identification card. }\end{array}$ & 3.31 & 1.16 & 9 \\
\hline 15 & $\begin{array}{l}\text { Performance scale could be measuring performance } \\
\text { levels. }\end{array}$ & 3.11 & 1.15 & 12 \\
\hline 16 & $\begin{array}{l}\text { Availability continuous review of standards performance } \\
\text { thereof proof objectives occur against each phase of } \\
\text { performance. }\end{array}$ & 2.89 & 1.10 & 17 \\
\hline 17 & $\begin{array}{l}\text { Management desk establish obvious criteria for all } \\
\text { employees' application in link with various duties. }\end{array}$ & 2.99 & 1.08 & 15 \\
\hline \multirow[t]{2}{*}{18} & $\begin{array}{l}\text { Performance evaluation criteria dividend based on job } \\
\text { type within precise department. }\end{array}$ & 3.30 & 1.07 & 10 \\
\hline & Overall mean value & 3.36 & 0.60 & \\
\hline
\end{tabular}

The results in table (8) showed the staff members 'performance mean value is equal to (3.36) with (St. dv:0.60). Therefore, it could be concluded that burnout has a moderate effect on staff members' performance in KAU. However, the result showed that, there are various positive indications presenting that the staff members' performance is not affected by burnout: majority of staff members strongly agreed that they are capable to deal with advanced technology and systems, and they are capable to find alternative solutions to resolve business difficulties.

Table (9) Multiple regression correlation relationship between burnout's dimensions and Staff members' performance.

\begin{tabular}{|c|c|c|c|c|c|c|}
\hline Model & Coefficients & Beta & T-test & Sig. & $\mathrm{F}$ & Sig. \\
\hline Constant & 30.22 & & $6.419 * *$ & 0.00 & \multirow{4}{*}{$58.92 * *$} & \multirow{4}{*}{0.00} \\
\hline Emotional exhaustion & -0.225 & -0.144 & $-2.924 * *$ & 0.004 & & \\
\hline Depersonalization & 0.098 & 0.035 & 0.730 & 0.47 & & \\
\hline Personal accomplishment & 1.309 & 0.448 & $10.07 * *$ & 0.00 & & \\
\hline \multicolumn{2}{|l|}{${ }^{2} \mathrm{R}=0.263$} & \multicolumn{5}{|c|}{$\mathrm{Adj}^{2} \mathrm{R}=0.258$} \\
\hline
\end{tabular}

**indicated that T-test is significant at the (0.01) significant level

**indicated that F-value is significant at the (0.01) significant level. 
The results in table (9) revealed that the F-value is significant at the (0.01) significant level, which indicated that, the multiple regression model used is efficient to estimate the effect of burnout dimensions on the Staff members' performance; which is supported by the coefficient of determination $\left(\mathrm{R}^{2}\right)$ value reaching $(0.263)$. This means the dimensions of burnout have the power to estimate the changes on the KAU Staff members' performance by $26.0 \%$ approximately.

\subsection{Section two: Results of Testing Research Hypotheses}

- (H1): stated that "There is significant and negative impact of emotional exhaustion dimension of job burnout on (KAU) Staff Members' performance".

Table (10): Person's Correlation coefficient between the independent variable (emotional exhaustion) and the dependent variable Staff members' Performance

\begin{tabular}{|l|c|c|}
\hline \hline Variables & \multicolumn{2}{|c|}{ Staff members' Performance } \\
\hline & Correlation Coefficient & P-value \\
\hline Emotional exhaustion & $-0.330^{* *}$ & 0.00 \\
\hline
\end{tabular}

**indicated that correlation coefficient is significant at the (0.01) level

The result showed that there is statistically significant and inverse correlation relationship between emotional exhaustion and the Staff members' performance at the significant level (0.01). This negative value indicated that emotional exhaustion, has a negative impact on Staff members' performance, but it could be considered as a weak impact. Hence, the hypothesis is accepted.

-(H2): stated that "There is significant and negative impact of depersonalization dimension of job burn out on (KAU) Staff Members' Performance".

Table (11)Person's Correlation coefficient between the independent variable (depersonalization) and the dependent variable Staff members' Performance.

\begin{tabular}{||l|c|c|}
\hline Variables & \multicolumn{2}{|c|}{ Staff members' Performance } \\
\hline & Correlation Coefficient & P-value \\
\hline depersonalization & $-0.233^{* *}$ & 0.00 \\
\hline
\end{tabular}

**indicated that correlation coefficient is significant at the (0.01) level

The result showed that there is statistically significant and inverse correlation relationship between depersonalization and the Staff members' performance at the significant level (0.01). This negative value indicated that depersonalization has a negative impact on Staff members' performance in KAU. However, the value is low, so the impact is weak. Hence, the hypothesis is accepted.

-(H3) stated that "There is significant and positive impact of personal accomplishment dimension of job burnout on (KAU) Staff Members' performance”.

Table (12) Person's Correlation coefficient between the independent variable (depersonalization) and the dependent variable Staff members' Performance.

\begin{tabular}{||l|c|c|}
\hline Variables & \multicolumn{2}{|c|}{ Staff members' Performance } \\
\hline & Correlation Coefficient & P-value \\
\hline Decrease of personal accomplishment & $0.499^{* *}$ & 0.00 \\
\hline
\end{tabular}

Result in table (12) revealed that there is statistically and positive relationship between personal accomplishment and Staff members' performance, as the value of correlation coefficient is reaching (0.499), and significant at the (0.01) significant level. This positive value indicated that personal accomplishment affects positively on the staff performance and vice versa.

\section{Discussion and Recommendations}

5.1. Discussion of the level of burnout of staff members at KAU in the dimensions of (Emotional Exhaustion, Depersonalization, and Personal Accomplishment)

The results demonstrated moderate levels of burnout at the institution as mean is (2.96) which indicated that employees at KAU continue to experience some instances of burnouts. A similar study across Jordan universities found average levels of job burnouts across both public and private institutions as mean is (3.42) and (3.37) respectively(Khdour et al., 
2015). This finding indicated that problems are not limited to the target university. Workers in many learning institutions continue to contend with the issue.

\subsubsection{Emotional exhaustion}

The results of the survey on the emotional exhaustion dimension of burnout suggest that it had a moderate impact on employees at the King Abdul-Aziz University. A similar study by Gorji (2011) also noted high-level emotional exhaustion as a principal aspect of burnout in addition to depersonalization. According to the outcomes, the highest ranked factors that were associated with emotional exhaustion were job-related frustration, emotional exhaustion resulting from work, and emotional drain. In addition, Freudenberg (1974) identified workplace frustration as a principal contributor to the problem.

As noted by Maslach et al., (2001), the risk factors of high-level frustrations include the absence of motivation, limited growth opportunities, and the presence of a worrying atmosphere. These dynamics contribute emotional drain which, in turn, leads to instances of burnout. Kugiejko (2015) also associated high workloads with increased stress and frustration levels. If the current trend persists, the university is likely to experience high levels of burnout. The management needs to implement appropriate strategies to contain the situation.

\subsubsection{Depersonalization}

The impact of depersonalization was not significant at the university, suggesting that the majority of the workers do not experience repeated feelings of being detached from themselves. This finding is comparable with that of Khdour et al. (2015) who ranked this variable as the lowest among the dimensions. Therefore, it can be concluded that depersonalization is not a significant factor when analyzing the impacts of burnouts on performance at KAU.

Depersonalization has been considered a reliable measure of burnout and has a drastic impact on performance (Gorji, 2011; Maslach et al., 2001). However, the insignificant impact of depersonalization at the university does not suggest the workers are free of issues related to the problem. According to the findings, the aspect of depersonalization that received the highest ranking was the fact that some workers felt that they were recipients of blames for many problems. This state is likely to contribute to high stress levels, a situation that contributes to burnouts (Demir et al., 2003). Managers need to evaluate the way they distribute blames across different employees. Otherwise, they may overburden some workers and impel them to experience recurring instances of stress.

\subsubsection{Personal accomplishment}

Personal accomplishment attained the highest rating suggesting that workers at the university had high levels of selfefficacy. Khdour et al. (2015) identified personal performance as the highest ranked dimension of job burnout. The implication is that employees who demonstrate high levels of self-efficacy experience low frequencies of burnouts. In fact, low sense of personal achievement has been associated with high levels of exhaustion (Lee, \&Ashforth, 1993). This fact probably explains the fact that workers at KAU had lower levels of burnouts than those analyzed by Khdour et al., (2015). All the items of this dimension recorded above average means. However, the highest rated item was the ability of a worker to solve the problems of their clients, implying the need for organizations to equip workers with resources and skills that enable them to address the needs of their recipients.

\subsection{Discussion on the (Measure of Performance)}

Findings assessed the extent to which job burnout affected the performance of the staff members of the target institution. The result of this analysis indicated that burnouts had moderate impacts on employee performance at KAU. This outcome is in agreement with several other studies that have found positive links between the two. For example, Zang and Feng (2011) established a significant association between job contentment and the intention to quit voluntarily. The mediating factor between the two variables was burnout. Khdour et al. (2015) who established higher job burnout levels in public universities than in private institutions also noted reduced satisfaction rates in the former, suggesting a negative correlation between burnouts and workplace contentment. Similar findings were noted by Bakker and Oerlemans (2016) who associated burnout with reduced satisfaction.

The dimensions that were found to have significant impacts on employee performance were personal accomplishment and emotional exhaustion. Depersonalization was noted to have insignificant influence on performance. According to Khdour et al. (2015), only one dimension of burnout, personal achievement, was associated with employee satisfaction. The implication is that although the three aspects influence performance, emotional exhaustion and personal accomplishment are the most significant. Therefore, organizational strategies that aim at minimizing burnouts should put much emphasis on the two.

The notable dynamics that contributed to the moderate impact of burnout on performance were the high capability to deal with changing technologies, high match between employee skills and job specification, and the availability of 
alternative solutions to solve particular problems. The university's performance in these aspects was above average implying that many workers were able to conform to emerging technologies, reduce the gaps between their skills and the routine tasks, and had access to different alternatives to problem solutions. These results confirm Khdour et al. (2015)'s assertion that incompetency and the absence of consistency between job specification and employee skills are potential contributors to job burnouts. Organizations need to ensure that they equip workers with necessary skills that match expected tasks to reduce instances of low-performance accomplishment.

\subsection{Recommendations}

The study makes the following recommendations based on the main outcomes:

1. The findings have established workplace frustration as a leading contributor to burnouts. Therefore, managers need to conduct regular assessment of their staff and work at removing factors that may lead to frustration.

2. High levels of personal accomplishment have been associated with low occurrences of burnouts. Institutions need to invest to equip employees with sufficient skills and resources to increase their confidence. Achieving this objective may entail regular training and ensuring that workers adapt to the current technologies.

3. Managers should work at improving the designs of the jobs in their organizations to increase motivation. High levels of motivation can result in reduced burnout rates.

4. The management needs to pay attention to the effects resulting from emotional exhaustion. Possible approaches of managing the issue include appropriate entertainment programs and regular checkups for the psychological state of each staff member.

5. Workplace burnouts are linked with extended work hours and rigid schedules. Accordingly, the university should design employee work timetables in a way that minimize the possible effects of burnouts dimensions on staff performance.

\subsection{Conclusion}

The findings of the results suggest that workers at the institution experience instances of occupational burnouts. They further imply that the three dimensions have varied impacts on the performance of employees at the university. Many of them are not affected by depersonalization, indicating that most of them are comfortable with their workstations. The majority of these employees experience sufficient levels of personal accomplishment. However, emotional exhaustion presents a great risk of burnouts among the workers. The management needs to implement strategies for improving the emotional status of employees at the university.

The findings also suggest that gender differences affect the effects of burnouts regarding emotional exhaustion and personal accomplishment. Women are at high risk regarding the former. The dimensions that have significant associations with both age and experience: depersonalization and personal accomplishment. The link between the two demographic factors and emotional exhaustion is insignificant. These outcomes imply that managers need to design mechanisms that focus on improving the welfare of the female worker.

\section{References}

Afzalur, M. R. (2016). Reducing job burnout through effective conflict management strategy. Current Topics in Management, 18(1), 201-212.

Bakker, A. \& Oerlemans, W. (2016). Momentary work happiness as a function of enduring burnout and work engagement. The Journal of Psychology, 150(6), 755-778.

Demir, A., Ulusoy, M. \&Ulusoy, MF (2003). Investigation of factors influencing burnout levels in the professional and private lives of nurses. International Journal of Nursing Studies, 40(8), 807-827.

Espeland, K. E. (2006). Overcoming burnout: How to revitalize your career. The Journal of Continuing Education in Nursing, 37(4), 178-184.

Freudenberger, H. (1974). Staff Burnout. Journal of Social Issues, 30, 159-165.

Gorji, M. (2011). The effect of job burnout dimension on employees' performance. International Journal of Social Science and Humanity, 1(4), 243-26.

Halbesleben, J. R. B. (2003). Assessing the construct validity of alternative measures of burnout. International Journal of Social Science and Humanity, 2(1), 15-26.

Kugiejko, M. (2015). A professional skill set of a teachers and university lecturer in relation to the causes and prevention of job burnout. Problems of Education in the 21st Century, 67, 40-51. Retrieved from http://oaji.net/articles/2015/457-1449572275.pdf. 
Khdour, N. J., Omar, D., \& Martin, H. (2015). The effect of job burnout on employees' satisfaction: A comparison study between public universities and private universities in Jordan. The Journal of Management Research, 7(4), 54-80. doi: 10.5296/jmr.v7i4.7790

Lee, R. T., \&Ashforth, B. E. (1993). A longitudinal study of burnout among supervisors and managers: Comparisons between the Leiter and Maslach (1988) and Golembiewski et al. (1986) models. Organizational Behavior and Human Decision Processes, 54(3), 369-398.

Maslach, C. (1982). Burnout: The Cost of Caring. Englewood Cliffs, NJ: Prentice-Hall.

Maslach, C. Jackson, S. E. \&Leiter, M. P. (1996). MBI: The Maslach Burnout Inventory manual (3rd ed.). Palo Alto, CA: Consulting Psychologists Press.

Maslach, C., Schaufeli, W.B., \&Leiter, M.P. (2001).Job burnout.Annual Review of Psychology, 52, 397-422.

Naser, K., Mohammed, W.R. and Nuseibeh, R. (2015), Comparison Study between Public and Private Universities in Jordanof organizational burnout, Psychology, 23, 12-20.

Schaufeli, W. B., \&Enzmann, D. (1998). The burnout companion to study and research: A critical analysis. London: Taylor and Francis.

Wendy M. Novicoff (2009). Recognizing and preventing burnout among orthopaedic leaders. Clinical Orthopaedics and Related Research, 467(2), 558-565.

Zhang Y, Feng X.(2011). The relationship between job satisfaction, burnout, and turnover intention among physicians from urban state-owned medical institutions in Hubei, China: a cross-sectional study. 